\title{
Rhabdomyolysis and acute kidney injury in patients with traumatic spinal cord injury
}

\author{
Rita Galeiras, Mónica Mourelo, Sonia Pértega , Amanda Lista, Mª Elena Ferreiro², \\ Sebastián Salvador ${ }^{2}$, Antonio Montoto ${ }^{2}$, Antonio Rodríguez ${ }^{2}$
}

\section{흔}

Background: Patients with acute traumatic spinal cord injuries ( $\mathrm{SCls}$ ) exhibit factors that, in other populations, have been associated with rhabdomyolysis. Purpose: The aim of the study is to determine the incidence of rhabdomyolysis in patients with acute traumatic $\mathrm{SCl}$ admitted to the Intensive Care Unit (ICU), as well as the development of secondary acute kidney injury and associated factors. Study Design and Setting: This was an observational, retrospective study. Patient Sample: All adult patients admitted to the ICU with acute traumatic SCI who presented rhabdomyolysis, diagnosed through creatine phosphokinase (CPK) levels $>500 \mathrm{IU} / \mathrm{L}$. Outcome Measures: Incidence of rhabdomyolysis and subsequent renal dysfunction was calculated. Materials and Methods: Data about demographic variables, comorbidity, rhabdomyolysis risk factors, and variables involving $\mathrm{SCl}$, severity scores, and laboratory parameters were obtained from clinical records. Multivariate logistic regression was used to identify renal injury risk factors. Results: In 2006-2014, 200 patients with acute SCl were admitted to ICU. Of these, 103 had rhabdomyolysis (incidence $=51.5 \%$; $95 \%$ confidence interval $[\mathrm{Cl}]$ : $44.3 \%-58.7 \%$ ). The most typical American Spinal Injury Association classification was A (70.3\%). The injury severity score was $30.3 \pm 12$.I and sequential organ failure assessment (SOFA) score was $5.6 \pm 3.3$ points. During their stay, 57 patients $(55.3 \% ; 95 \% \mathrm{Cl}: 45.2 \%-65.4 \%)$ presented renal dysfunction (creatinine $\geq 1.2 \mathrm{mg} / \mathrm{dL}$ ). In the multivariate analysis, variables associated with renal dysfunction were creatinine at admission (odds ratio $[O R]=9.20 ; P=0.006$ ) and hemodynamic SOFA score the day following admission (OR $=1.33 ; P=0.024)$. Creatinine was a better predictor of renal dysfunction than the peak CPK value during the rhabdomyolysis (area under the receiver operating characteristic curve: 0.91 vs. 0.63 , respectively). Conclusions: Rhabdomyolysis is a frequent condition in patients with acute traumatic $\mathrm{SCl}$ admitted to the ICU, and renal dysfunction occurs in half of the cases. Creatinine values should be requested starting at the admission while neither the peak CPK values nor the hemodynamic SOFA scores could be used to properly discriminate between patients with and without renal dysfunction.

Keywords: Acute kidney injury, rhabdomyolysis, spinal cord injuries

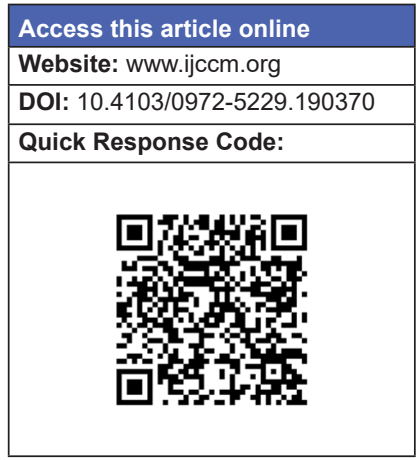

From:

Critical Care Unit, Complexo Hospitalario Universitario de A Coruña,

University of A Coruña, ${ }^{1}$ Clinical Epidemiology and Biostatistics Unit,

Complexo Hospitalario Universitario de A Coruña, University of A Coruña,

2Spinal Cord Injury Unit, Complexo Hospitalario Universitario de A Coruña,

University of A Coruña. CP: 15006 A Coruña, Spain

Correspondence:

Dr. Rita Galeiras, Critical Care Unit, Complexo Hospitalario Universitario de A Coruña, Instituto de Investigación Biomédica de A Coruña,

SERGAS, Universidade da Coruña, As Xubias, 15006 A Coruña, Spain

E-mail: ritagaleiras@ hotmail.es
This is an open access article distributed under the terms of the Creative Commons Attribution-NonCommercial-ShareAlike 3.0 License, which allows others to remix, tweak, and build upon the work non-commercially, as long as the author is credited and the new creations are licensed under the identical terms.

For reprints contact: reprints@ @medknow.com

How to cite this article: Galeiras R, Mourelo M, Pértega S, Lista A, Ferreiro ME, Salvador $\mathrm{S}$, et al. Rhabdomyolysis and acute kidney injury in patients with traumatic spinal cord injury. Indian J Crit Care Med 2016;20:504-12. 


\section{Introduction}

Rhabdomyolysis is a clinical emergency characterized by the rapid breakdown of skeletal muscle cells. It may be caused by trauma or nontraumatic factors, ${ }^{[1-3]}$ such as drugs, alcohol, ischemia, infectious diseases, and genetic disorders, though it is often impossible to detect a specific trigger mechanism. Regardless of the cause, however, the physiopathological events include an increased concentration in intracellular calcium resulting either from direct damage to the sarcolemma (acquired) or from the failure to produce energy (genetic), which leads to the dysfunction of the Na/K2-ATPase and $\mathrm{Ca}^{2}$-ATPase pumps and to necrosis of skeletal muscle fibers. ${ }^{[4-6]}$

Rhabdomyolysis in an awake patient is characterized by myalgia, weakness, and reddish urine. Acute renal failure is the most significant complication, occurring at a rate of $17 \%-33 \%$ in various series. ${ }^{[7-9]}$ The mechanisms involved in kidney injury in patients with rhabdomyolysis include blockage of the renal tubules with myoglobin, damage from free oxygen radicals, and myoglobin-induced vasoconstriction of renal arterioles. ${ }^{[6]}$

Patients with acute traumatic spinal cord injuries (SCIs) exhibit factors that, in other populations, have been associated with rhabdomyolysis, such as high-impact injuries, other relevant traumas, immobilization, need for drugs during a hospital stay, thermal dysregulation, and hemodynamic instability, and could comprise a population at risk of rhabdomyolysis. A high index of suspicion is required for an early diagnosis of rhabdomyolysis, especially in the absence of pain and motility. The rate of rhabdomyolysis, however, and the factors related to the development of subsequent renal dysfunction have not been studied in patients with acute traumatic SCI. Identifying the risk of kidney injury would allow for establishing diagnostic and therapeutic strategies relevant to the prognosis.

The purpose of this study is to determine the incidence of rhabdomyolysis in patients with acute traumatic SCI who require admission to the Intensive Care Unit (ICU), their characteristics and mortality, as well as the development of secondary acute kidney injury and associated factors.

\section{Materials and Methods}

We conducted an observational, retrospective study to determine the characteristics of adult patients ( $\geq 18$ years old) with rhabdomyolysis and traumatic SCI who were admitted to an ICU between 2006 and 2014.
The study included patients admitted to the ICU diagnosed with acute traumatic SCI who presented with rhabdomyolysis, diagnosed through creatine phosphokinase (CPK) levels in excess of $500 \mathrm{IU} / \mathrm{L}$, as defined in the literature. ${ }^{[10-13]}$ Patients under 18 years of age and those whose admission had been delayed by $48 \mathrm{~h}$ or more from the time of the injury were excluded from the study.

Our center is a highly specialized hospital, and the Spinal Cord Injury Unit is a benchmark in the region of Galicia, which had an average population of 2,778,875 during the study period. Patients with acute traumatic $\mathrm{SCI}$ are admitted to the ICU if they need or are expected to need support for a failing organ. The CPK determination is a part of the laboratory test parameters requested for these patients on admission. When required, the acute kidney injury associated with rhabdomyolysis is prevented and/or treated by fluid resuscitation to prevent hypovolemia, by correcting metabolic acidosis, and by administering osmotic diuretics such as mannitol and loop diuretics. Identifying and treating the precipitating cause are of paramount importance. The rhabdomyolysis was treated in accordance with the instructions of the patient's intensivist.

\section{Definitions}

A diagnostic criterion for rhabdomyolysis was CPK in excess of $500 \mathrm{IU} / \mathrm{L}$. The catalytic activity of the CPK was determined according to the International Federation Clinical Chemistry (Dimension ${ }^{\circledR}$ clinical chemistry system. Newark, USA).

The trauma of the spinal cord was classified based on the categories of the American Spinal Injury Association (ASIA). ${ }^{[14]}$ The overall gravity of the trauma was assessed using the injury severity score (ISS). ${ }^{[15]}$ The level of consciousness was quantified using the Glasgow coma scale (GCS). ${ }^{[16]}$ Organ dysfunction was defined according to the sequential organ failure assessment (SOFA) scale. ${ }^{[17]}$ The body mass index was used to classify the patients as obese when its value was $\geq 30 \mathrm{~kg} / \mathrm{m}^{2}$.

\section{Parameters}

The parameters collected from medical records on admission were demographic (age and gender) and comorbidity (Charlson comorbidity index and arterial hypertension) variables, risk factors related in the literature to rhabdomyolysis (muscular necrosis, obesity, consumption of statins, antipsychotics, sedatives or alcohol, convulsions, anxiety, and hypo/ hyperthermia), variables involving the SCI (area of the 
spinal column affected with the column's sensory/motor level and the ASIA index), GCS, ISS, and laboratory analysis parameters relative to renal function (urea and creatinine) on admission. The SOFA score was calculated on admission in the first $24 \mathrm{~h}$ after admission and when the rhabdomyolysis was diagnosed. The time between admission and the rhabdomyolysis diagnosis, as well as the duration of the episode, was recorded. During the rhabdomyolysis episode, the initial and worse laboratory test values for CPK, creatinine, urea, potassium, calcium, phosphorus, lactate dehydrogenase (LDH), glutamic oxaloacetic transaminase (GOT), uric acid, albumin, and metabolic acidosis were recorded. Variables related to preventing and/or treating kidney dysfunction, ICU stay, and intrahospital mortality were also recorded.

\section{Sample size justification}

From 2006 to 2014, 200 patients with an acute SCI were admitted to the ICU. Of these, 103 had rhabdomyolysis (CPK >500 IU/L). This sample size makes it possible to determine the characteristics of patients with rhabdomyolysis and the incidence of renal dysfunction with a confidence interval (CI) of $95 \%$ (alpha $=0.05)$ and a precision of $\pm 9.6 \%$.

\section{Statistical analysis}

A descriptive analysis was performed. Quantitative variables were described as mean \pm standard deviation (SD) and median (range). Categorical variables were described as counts and percentages.

The incidence of renal dysfunction during ICU stay was determined, together with its 95\% CI. The Mann-Whitney test was used to compare the quantitative variables between patients with and without renal dysfunction. The Chi-square or Fisher's exact test was employed to compare qualitative variables between these groups of patients. The correlation among quantitative variables was assessed using Spearman's rho correlation coefficient. For multivariate analysis, a multiple logistic regression model was used to identify those variables independently associated with presenting kidney dysfunction during ICU stay.

The ability of different variables to predict renal dysfunction was expressed as the area under the receiver operating characteristics curve (AUC-ROC) and 95\% CI. Sensitivity, specificity, predictive values, and likelihood ratios were also computed for different cutoffs in those variables potentially associated with kidney dysfunction.

Values of $P<0.05$ were considered statistically significant. Statistical calculations were performed using the SPSS 19.0 statistical software suite (IBM Corp. Released 2010. IBMSPSS Statistics for Windows, Version 19.0. Armonk, NY: IBM Corp).

\section{Ethics}

The study was carried out according to the principles laid in the Declaration of Helsinki and ensuring compliance with Spanish Decree 29/2009, which regulates the use of and access to electronic medical records. Confidentiality was maintained in accordance with the current Spanish Data Protection Law (15/1999). The study protocol was approved by the local Ethics Committee.

\section{Results}

From 2006 to 2014, 200 patients with an acute SCI were admitted to the ICU. Of these, 103 had rhabdomyolysis (CPK >500 IU/L). The incidence of rhabdomyolysis was therefore $51.5 \%$ (95\% CI: $44.3 \%-58.7 \%$ ).

\section{Patient characteristics}

The demographic characteristics relative to the SCI and severity indices for patients with rhabdomyolysis are shown in Table 1 . The average age was $50.3 \pm 18.9$ years (median $=49.0$ years), and $80.6 \%$ of the cases were in men. Most had a low comorbidity, with an age-adjusted Charlson comorbidity index at admission of $1.1 \pm 2.0$ (median $=1.7)$.

The most frequent sensory-motor level was cervical $(41.7 \%)$ and the most typical ASIA index was A $(70.3 \%)$. As for the severity scales at admission, the ISS was $30.3 \pm 12.1$, the GCS was $13.7 \pm 3.1$, and the SOFA was $5.6 \pm 3.3$ points.

\section{Characteristics related to rhabdomyolysis}

The average time between admission and the onset of rhabdomyolysis was $0.3 \pm 0.5$ days, with the condition being detected on admission in $78.6 \%$ of the patients and lasting $5.1 \pm 3.1$ days (median $=4.0$ days). In addition to the presence of trauma, which is a common risk factor in patients who contract rhabdomyolysis, Table 2 shows the other relevant risk factors. Of note is the use of sedatives and/or analgesics in 100\% of the cases and thermoregulatory alterations in 93 patients (90.3\%). Rehydration in the first $24 \mathrm{~h}$ following the trauma was $4696.2 \pm 1994.7 \mathrm{ml}$. The average SOFA score on the day of the rhabdomyolysis was $5.6 \pm 3.4$ points $(0-5$ scale), with $37.8 \%$ of patients presenting renal dysfunction at the time (determined using the SOFA renal score).

The laboratory variables are also shown in Table 2. Kidney function was evaluated at admission based on 


\begin{tabular}{|c|c|c|c|c|c|}
\hline Variables & $n(\%)$ & Mean \pm SD & Median & Minimum & Maximum \\
\hline Age (years) & 103 & $50.3 \pm 18.8$ & 49.0 & 18 & 87 \\
\hline \multicolumn{6}{|l|}{ Gender } \\
\hline Male & $83(80.6)$ & & & & \\
\hline Female & $20(19.4)$ & & & & \\
\hline Age-adjusted Charlson comorbidity index & 103 & $I . I \pm 2.0$ & 1.7 & 0 & 9.7 \\
\hline Arterial hypertension & $20(19.4)$ & & & & \\
\hline \multicolumn{6}{|l|}{ Sensory/motor level } \\
\hline Cervical & $43(4 I .7)$ & & & & \\
\hline Dorsal & $50(48.5)$ & & & & \\
\hline Lumbar & $6(5.8)$ & & & & \\
\hline Cauda equina & $4(3.9)$ & & & & \\
\hline ASIA classification & 101 & & & & \\
\hline A & 7I (70.3) & & & & \\
\hline B & $14(13.9)$ & & & & \\
\hline C & $8(7.8)$ & & & & \\
\hline D & $7(6.9)$ & & & & \\
\hline $\mathrm{E}$ & I (I.0) & & & & \\
\hline GCS & 103 & $13.7 \pm 3.1$ & 15.0 & 3 & 15 \\
\hline$\leq 8$ & $9(8.7)$ & & & & \\
\hline $9-13$ & $8(7.8)$ & & & & \\
\hline$\geq 14$ & $86(83.5)$ & & & & \\
\hline Injury severity score & 103 & $30.3 \pm 12.1$ & 26.0 & I & 75 \\
\hline Total SOFA score at admission & 103 & $5.6 \pm 3.3$ & 5.0 & 0 & 12 \\
\hline Total SOFA score in first $24 \mathrm{~h}$ following admission & 103 & $5.8 \pm 3.2$ & 6.0 & 0 & 13 \\
\hline Length of ICU stay in days & 103 & $18.8 \pm 12.0$ & 18.0 & 2 & 52 \\
\hline Days between injury and admission to ICU & 103 & $0.6 \pm 2.4$ & 0 & 0 & 22 \\
\hline Intrahospital mortality & $17(16.5)$ & & & & \\
\hline Intra-ICU mortality & $3(2.9)$ & & & & \\
\hline
\end{tabular}

SD: Standard deviation; ASIA: American Spinal Injury Association; SOFA: Sequential Organ Failure Assessment; ICU: Intensive Care Unit; GCS: Glasgow coma scale

creatinine levels, with the average being $1.2 \pm 0.6 \mathrm{mg} / \mathrm{dL}$. In $34 \%$ of the cases, it was $\geq 1.2 \mathrm{mg} / \mathrm{dL}$. The average urea was $49.8 \pm 22.1 \mathrm{mg} / \mathrm{dL}$. In $67 \%$ of the patients, the maximum CPK value was recorded in the first $24 \mathrm{~h}$ after admission, with an average peak maximum CPK of $3761.3 \pm 5095.2 \mathrm{IU} / \mathrm{L}$ (median $=2232.0$ ). As for renal function, during the rhabdomyolysis, the average creatinine level was $1.3 \pm 0.8 \mathrm{mg} / \mathrm{dL}$, average urea was $69.3 \pm 27.3 \mathrm{mg} / \mathrm{dL}$, and the average hourly diuresis in the first $24 \mathrm{~h}$ after the rhabdomyolysis diagnosis was $88.5 \pm 31.1 \mathrm{ml} / \mathrm{h}$. As concerns the other laboratory analysis variables during the rhabdomyolysis episode, these showed the following average levels: LDH of $752.2 \pm 369.8 \mathrm{IU} / \mathrm{L}$, GOT 107.4 $\pm 109.4 \mathrm{IU} / \mathrm{L}$, uric acid $4.2 \pm 2.1 \mathrm{mg} / \mathrm{dL}$, albumin $2.9 \pm 0.5 \mathrm{~g} / \mathrm{dL}$, and a base deficit of $-2.6 \pm 6.5$.

As for the treatment when the rhabdomyolysis was diagnosed, rehydration was employed in $100 \%$ of the cases (average liquid in the first $24 \mathrm{~h}$ of $4614.8 \pm 1957.0 \mathrm{ml}$ ). In $22.3 \%$ of the cases, diuresis was forced using loop diuretics, and in $11.7 \%$ of the cases, urine alkalinization using bicarbonate was utilized. None of the patients required renal replacement therapy.

The mean length of ICU stay was $18.8 \pm 12.0$ days, with an in-hospital mortality of $16.5 \%$ (95\% CI: $8.8 \%-24.1 \%)$
(17 patients) and in-ICU of $2.9 \%$ (95\% CI: $0.6 \%-8.3 \%)$ (3 patients) [Table 1].

Incidence of renal dysfunction and associated factors

During their stay, 57 patients ( $55.3 \%$; $95 \%$ CI: $45.2 \%-65.4 \%$ ) presented renal dysfunction (creatinine $\geq 1.2 \mathrm{mg} / \mathrm{dL}$ ). These were compared with the 46 patients (44.7\%) with normal renal function [Table 3]. We did not find significant differences between the two groups when assessing comorbidity as per the age-adjusted Charlson comorbidity index, traumatic injury scales, or SOFA score on admission. Similarly, there was no correlation between the values of the age-adjusted Charlson comorbidity index or the ISS and the serum creatinine value during the rhabdomyolysis. This was in contrast to the SOFA score on the day of admission (rho $=0.222 ; P=0.024)$. The average fluid intake in the first $24 \mathrm{~h}$ after admission was similar in both groups (4905.6 vs. $4424.9 \mathrm{ml} ; P=0.091$ ), unlike the creatinine values at admission $(1.30$ vs. $0.99 \mathrm{mg} / \mathrm{dL}$; $P=0.000)$, the hemodynamic status on the $1^{\text {st }}$ day in the hospital as determined by the hemodynamic SOFA (1.8 vs. 1.7 points; $P=0.003)$, and peak CPK (4639.6 IU/L vs. $2673.1 \mathrm{IU} / \mathrm{L} ; P=0.023)$, which were higher in the group with kidney injury. As concerns the rhabdomyolysis treatment, the group with renal dysfunction received significant mannitol treatment $(14.0 \%$ vs. $2.2 \% ; P=0.040)$, this not being the case with other treatments. Both the ICU 


\begin{tabular}{|c|c|c|c|c|c|}
\hline Variables & $n(\%)$ & Mean \pm SD & Median & Minimum & Maximum \\
\hline Days from admission until rhabdomyolysis & 103 & $0.3 \pm 0.5$ & 0 & 0 & 2 \\
\hline 0 & $81(78.6)$ & & & & \\
\hline I & $17(16.5)$ & & & & \\
\hline 2 & $5(4.9)$ & & & & \\
\hline Duration of the rhabdomyolysis (days) & 103 & $5.1 \pm 3.1$ & 4.0 & I & 16 \\
\hline \multicolumn{6}{|l|}{ Rhabdomyolysis risk factors } \\
\hline Muscle necrosis & $\mathrm{I}(\mathrm{I} .0)$ & & & & \\
\hline Obesity & $4(3.9)$ & & & & \\
\hline Statins & $13(12.6)$ & & & & \\
\hline Antipsychotics & $17(16.5)$ & & & & \\
\hline Alcohol & $10(9.7)$ & & & & \\
\hline Convulsions & $\mathrm{I}(\mathrm{I} .0)$ & & & & \\
\hline Anxiety & $16(15.5)$ & & & & \\
\hline Sedatives & $103(100)$ & & & & \\
\hline Hyperthermia $\left(>39^{\circ} \mathrm{C}\right)$ & $20(19.4)$ & & & & \\
\hline Hypothermia $\left(<36^{\circ} \mathrm{C}\right)$ & $73(70.9)$ & & & & \\
\hline Rehydration in the first $24 \mathrm{~h}$ after the trauma $(\mathrm{ml})$ & 101 & $4696.2 \pm 1994.6$ & 4300.0 & 1175 & 14,340 \\
\hline \multicolumn{6}{|l|}{ Laboratory analysis results at admission } \\
\hline Potassium (mEq/L) & 103 & $4 . I \pm 0.7$ & 4.I & 1.9 & 6.2 \\
\hline Calcium (mg/dL) & 81 & $7.6 \pm 0.6$ & 7.6 & 5.8 & 9.2 \\
\hline Phosphorus (mg/dL) & 41 & $3.1 \pm 0.9$ & 3.0 & 1.2 & 4.8 \\
\hline Creatinine $(\mathrm{mg} / \mathrm{dL})$ & 103 & $1.2 \pm 0.6$ & I.I & 0.39 & 6.00 \\
\hline Urea $(\mathrm{mg} / \mathrm{dL})$ & 103 & $49.8 \pm 22.1$ & 46.0 & 10 & $|4|$ \\
\hline \multicolumn{6}{|l|}{$\begin{array}{l}\text { Laboratory analysis values during } \\
\text { rhabdomyolysis (worst value) }\end{array}$} \\
\hline CPK (IU/L) & 103 & $376 \mid .3 \pm 5095.2$ & 2232.0 & 544 & 34,768 \\
\hline $\begin{array}{l}\text { Patients with peak CPK on day } 0 \text { or I since the } \\
\text { spinal cord injury }\end{array}$ & $69(67)$ & & & & \\
\hline Creatinine (mg/dL) & 103 & $1.3 \pm 0.8$ & 1.2 & 0.5 & 8.7 \\
\hline Creatinine $\geq 1.2(\mathrm{mg} / \mathrm{dL})$ & $57(55.3)$ & & & & \\
\hline Urea (mg/dL) & 103 & $69.3 \pm 27.3$ & 64.0 & 25 & 169 \\
\hline LDH (IU/L) & 101 & $752.2 \pm 369.8$ & 658.0 & 65 & 2222 \\
\hline GOT (IU/L) & 102 & $107.4 \pm 109.4$ & 77.5 & 19 & 849 \\
\hline Uric acid (mg/dL) & 90 & $4.2 \pm 2.0$ & 4.2 & 1.0 & 10.8 \\
\hline Albumin (gr/dL) & 96 & $2.9 \pm 0.5$ & 2.9 & 1.7 & 4.4 \\
\hline Base deficit & 102 & $-2.6 \pm 6.5$ & -4.1 & -19.6 & 11.0 \\
\hline Total SOFA score on $\left.\right|^{\text {st }}$ day of rhabdomyolysis & 103 & $5.5 \pm 3.4$ & 5.0 & 0 & 12 \\
\hline Renal SOFA score on $\left.\right|^{\text {st }}$ day of rhabdomyolysis & 103 & $0.4 \pm 0.5$ & 0 & 0 & 2 \\
\hline $\begin{array}{l}\text { Renal SOFA score } \geq \text { I on }\left.\right|^{\text {st }} \text { day of } \\
\text { rhabdomyolysis }\end{array}$ & $39(37.8)$ & & & & \\
\hline $\begin{array}{l}\text { Average diuresis during first } 24 \mathrm{~h} \text { of the } \\
\text { rhabdomyolysis }(\mathrm{ml} / \mathrm{h})\end{array}$ & 103 & $88.5 \pm 31.1$ & 85.0 & 41 & 210 \\
\hline Treatment during the rhabdomyolysis & $34(33.0)$ & & & & \\
\hline Liquids (ml/24 h) & $103(100)$ & $46 \mid 4.8 \pm 1957.0$ & 4200.0 & 550 & 14,340 \\
\hline Mannitol & $9(8.7)$ & & & & \\
\hline Bicarbonate & $12(11.7)$ & & & & \\
\hline Loop diuretics & $23(22.3)$ & & & & \\
\hline Hemofiltration & 0 & & & & \\
\hline Albumin & 0 & & & & \\
\hline
\end{tabular}

SD: Standard deviation; SOFA: Sequential Organ Failure Assessment; CPK: Creatine phosphokinase; LDH: Lactate dehydrogenase; GOT: Glutamic oxaloacetic transaminase

stay $(19.4$ days vs. 18.1 days; $P=0.717)$ and mortality $(1.8 \%$ vs. $4.3 \% ; P=0.585$ ) were similar in both groups.

After adjusting in the multivariate analysis for creatinine at admission, maximum CPK value during the rhabdomyolysis, and the hemodynamic SOFA the day following admission, the variables significantly associated with renal dysfunction were creatinine at admission (odds ratio $[\mathrm{OR}]=9.20 ; P=0.006$ ) and the hemodynamic SOFA score the day following admission $(\mathrm{OR}=1.33 ; P=0.024)$.
Creatinine at admission thus proved to be a better predictor of renal dysfunction than the peak CPK value during the rhabdomyolysis, with an AUC-ROC of 0.91 (95\% IC $=0.85-0.97)$ and 0.63 (95\% CI: 0.52-0.74), respectively [Figure 1]. Sensitivity, specificity, predictive values, and likelihood ratios were also calculated at various cutoff points for the initial creatinine, CPK, and hemodynamic SOFA on the day following admission [Table 4]. This showed that initial creatinine values $\geq 1.1 \mathrm{mg} / \mathrm{dL}$ exhibit good sensitivity $(77.2 \% ; 95 \%$ CI: 65.4-89.0), specificity (89.1\%; 95\% CI: 79.1-99.2), 


\begin{tabular}{|c|c|c|c|c|c|c|c|}
\hline \multirow[t]{2}{*}{ Variables } & \multirow[t]{2}{*}{$\begin{array}{l}\text { Correlation } \\
\text { coefficient }\end{array}$} & \multirow[t]{2}{*}{$P$} & \multicolumn{2}{|c|}{$\begin{array}{c}\text { Creatinine } \geq 1.2(\mathrm{mg} / \mathrm{dL}) \\
\quad n=57(55.34 \%)\end{array}$} & \multicolumn{2}{|c|}{$\begin{array}{c}\text { Creatinine }<1.2(\mathrm{mg} / \mathrm{dL}) \\
n=46(44.66 \%)\end{array}$} & \multirow[t]{2}{*}{$P$} \\
\hline & & & Mean \pm SD & Median & Mean \pm SD & Median & \\
\hline Age & 0.213 & 0.031 & $53.1 \pm 18.5$ & 56 & $46.7 \pm 18.9$ & 44.5 & 0.068 \\
\hline Gender (\%) & & - & & & & & 0.300 \\
\hline Male & - & & $84.2(48)$ & & $76.1(35)$ & & \\
\hline Female & - & & $15.8(9)$ & & $23.9(11)$ & & \\
\hline \multicolumn{8}{|l|}{ Comorbidity } \\
\hline $\begin{array}{l}\text { Age-adjusted Charlson comorbidity } \\
\text { Arterial hypertension, \% }\end{array}$ & 0.174 & 0.079 & $\begin{array}{l}1.9 \pm 2.0 \\
65.0(13)\end{array}$ & 1.5 & $\begin{array}{l}1.5 \pm 2.0 \\
35.0(7)\end{array}$ & 0.5 & $\begin{array}{l}0.140 \\
0.333\end{array}$ \\
\hline \multicolumn{8}{|l|}{ Injury scales } \\
\hline Injury severity score & -0.157 & 0.114 & $29.1 \pm 11.7$ & 26.0 & $31.9 \pm 12.6$ & 26.0 & 0.422 \\
\hline ASIA level A & & & $59.2 \%(42)$ & & $40.8 \%(29)$ & & 0.145 \\
\hline Total SOFA score at admission & 0.222 & 0.024 & $6.1 \pm 3.2$ & 5.0 & $5.0 \pm 3.4$ & 5.0 & 0.062 \\
\hline \multicolumn{8}{|l|}{ Risk factors for kidney injury } \\
\hline $\begin{array}{l}\text { Hemodynamic SOFA score in the } \\
\text { first } 24 \mathrm{~h} \text { after admission }\end{array}$ & 0.235 & 0.017 & $2.3 \pm 1.8$ & 3.0 & $1.3 \pm 1.6$ & 0 & 0.003 \\
\hline $\begin{array}{l}\text { Rehydration in the first } 24 \mathrm{~h} \text { after } \\
\text { the trauma }(\mathrm{ml})\end{array}$ & 0.128 & 0.198 & $4905.6 \pm 2131.7$ & 4660.0 & $4424.9 \pm$ I 789.1 & 3800.0 & 0.091 \\
\hline Creatinine at admission $(\mathrm{mg} / \mathrm{dL})$ & 0.734 & 0 & $1.3 \pm 0.3$ & 1.2 & $1.0 \pm 0.8$ & 0.90 & 0 \\
\hline Peak CPK (IU/L) & 0.240 & 0.015 & $4639.6 \pm 6160.9$ & 2459.0 & $2673.1 \pm 3069.6$ & 1760.5 & 0.023 \\
\hline \multicolumn{8}{|l|}{ Laboratory test abnormalities } \\
\hline Potassium (mEq/L) & 0.128 & 0.197 & $4.2 \pm 0.7$ & 4.20 & $4.0 \pm 0.6$ & 4.10 & 0.259 \\
\hline Calcium (mg/dL) & 0.036 & 0.752 & $7.7 \pm 0.7$ & 7.80 & $7.5 \pm 0.8$ & 7.60 & 0.466 \\
\hline Phosphorus (mg/dL) & 0.243 & 0.126 & $3.3 \pm 0.9$ & 3.20 & $3.0 \pm 1.0$ & 2.85 & 0.430 \\
\hline Uric acid (mg/dL) & 0.451 & 0 & $4.9 \pm 1.9$ & 4.95 & $3.5 \pm 1.9$ & 3.25 & 0 \\
\hline Albumin (g/dL) & -0.159 & 0.122 & $2.9 \pm 0.5$ & 2.90 & $3.0 \pm 0.5$ & 2.95 & 0.418 \\
\hline Base deficit & -0.180 & 0.070 & $-3.5 \pm 6.8$ & -4.7 & $-1.5 \pm 6.0$ & -3.5 & 0.191 \\
\hline $\begin{array}{l}\text { Average diuresis in the first } 24 \mathrm{~h} \text { of } \\
\text { the rhabdomyolysis }(\mathrm{ml} / \mathrm{h})\end{array}$ & -0.030 & 0.015 & $87.1 \pm 29.2$ & 85.0 & $90.2 \pm 33.5$ & 83.5 & 0.763 \\
\hline \multicolumn{8}{|l|}{ Treatment following diagnosis, \% } \\
\hline Mannitol & & & $14.0(8)$ & & $2.2(\mathrm{I})$ & & 0.040 \\
\hline Bicarbonate & & & $17.55(10)$ & & $4.3(2)$ & & 0.061 \\
\hline Furosemide & & & $22.8(13)$ & & $21.7(10)$ & & 0.545 \\
\hline Length of ICU stay in days & 0.056 & 0.571 & $19.4 \pm 12.6$ & 18 & $18.1 \pm 11.4$ & 18 & 0.717 \\
\hline Intra-ICU mortality, \% & - & - & $1.8(1)$ & & $4.3(2)$ & & 0.585 \\
\hline Intrahospital mortality, \% & - & - & $17.5(10)$ & & $15.2(7)$ & & 0.752 \\
\hline
\end{tabular}

SD: Standard deviation; ASIA: American Spinal Injury Association; SOFA: Sequential Organ Failure Assessment; ICU: Intensive Care Unit; CPK: Creatine phosphokinase

and adequate positive $(89.8 \%$; $95 \%$ CI: $80.3-99.3)$ and negative $(75.9 \%$, 95\% CI: 63.6-88.3) predictive values. In contrast, no cutoff points were found for either CPK or hemodynamic SOFA values that could be used to properly discriminate between patients with and without renal dysfunction.

\section{Discussion}

We studied episodes of rhabdomyolysis in patients admitted to an ICU after an acute traumatic SCI and the factors related to secondary kidney injury in these patients.

$51.5 \%$ of the patients with an acute traumatic SCI admitted to the ICU presented with rhabdomyolysis. CPK levels were moderately elevated (mean \pm SD: $3761.3 \pm 5095.2 \mathrm{IU} / \mathrm{L})$ though the patients had endured serious accidents (ISS mean \pm SD: $30.3 \pm 12.1$; ASIA A: $70.3 \%$ of cases) requiring immobilization for a certain period. The patients were young (median age: 49) and mostly male, which could be explained by the higher rate of exposure to $\mathrm{SCI}$ and other risk factors. In addition to the trauma and sedation, $86.7 \%$ of the patients exhibited at least one of the other risk factors analyzed. The start of the rhabdomyolysis episode was detected as part of the admission laboratory work in $78.6 \%$ of the patients.

Rhabdomyolysis is a condition with a wide range of clinical expression. ${ }^{[7]}$ The kidney injury associated with rhabdomyolysis results from vasoconstriction with decreased renal perfusion and intraluminal deposits of myoglobin, of its breakdown products and of uric acid, which causes obstruction and tubular damage. ${ }^{[18,19]}$ The factors that appear to be involved in the appearance of kidney injury in patients with rhabdomyolysis are glomerular filtration rate, metabolic acidosis, CPK levels, and presence of myoglobin in urine ${ }^{[6,19]} \mathrm{A}$ small increase in serum creatinine could indicate a significant decrease in glomerular filtration. Acidemia could facilitate the precipitation of myoglobin in the renal tubule. The 


\begin{tabular}{|c|c|c|c|c|c|c|}
\hline \multirow[t]{2}{*}{ Variables } & \multicolumn{6}{|c|}{$95 \% \mathrm{Cl}$} \\
\hline & Sensitivity & Specificity & $\begin{array}{c}\text { Positive } \\
\text { predictive value }\end{array}$ & $\begin{array}{c}\text { Negative } \\
\text { predictive value }\end{array}$ & $\begin{array}{c}\text { Positive } \\
\text { likelihood ratio }\end{array}$ & $\begin{array}{c}\text { Negative } \\
\text { likelihood ratio }\end{array}$ \\
\hline \multicolumn{7}{|c|}{ Initial creatinine $(\mathrm{mg} / \mathrm{dL})$} \\
\hline$\geq 0.8$ & $98.2(94.0-100.0)$ & $26.1(12.3-39.9)$ & $62.2(51.7-72.8)$ & $92.3(51.7-72.8)$ & $1.3(1.1-1.6)$ & $0.1(0.0-0.5)$ \\
\hline$\geq 0.9$ & $96.5(90.9-100)$ & $50.0(34.5-65.5)$ & $70.5(59.8-8 I-3)$ & $92.0(79-4-59.8)$ & $1.9(1.4-2.6)$ & $0.1(0.0-0.3)$ \\
\hline$\geq 1$ & $89.5(80.6-98.3)$ & $69.6(55.2-83.9)$ & $78.5(67.8-89.2)$ & $84.2(71.3-97.1)$ & $2.9(1.9-4.6)$ & $0.1(0.2-0.1)$ \\
\hline$\geq 1.1$ & $77.2(65.4-89.0)$ & 89.1 (79.1-99.2) & $89.8(80.3-99.3)$ & $75.9(63.6-88.3)$ & $7.1(3.1-16.4)$ & $0.3(0.2-0.4)$ \\
\hline$\geq 1.2$ & $59.6(46.0-73.3)$ & $97.8(92.5-100.0)$ & $97.1(90.2-100.0)$ & $66.2(54.2-78.2)$ & $27.44(3.9-192.9)$ & $0.4(0.3-0.6)$ \\
\hline \multicolumn{7}{|l|}{ CPK (IU/L) } \\
\hline$\geq 1000$ & $86.0(76.1-95.9)$ & $23.9(10.5-37.3)$ & $58.3(47.2-69.5)$ & $58.0(33.1-82.7)$ & I.I (0.9-I.4) & $0.6(0.3-1.3)$ \\
\hline$\geq 5000$ & $22.8(\mid \mathrm{I} .0-34.6)$ & $89.1(79.1-99.2)$ & $72.2(48.8-95.7)$ & $48.2(37.0-59.5)$ & $2.1(0.8-5.5)$ & $0.9(0.7-1.0)$ \\
\hline$\geq 10,000$ & $8.8(0.6-17.0)$ & $97.8(92.5-100.0)$ & $83.3(45.2-100.0)$ & $46.4(36.0-56.8)$ & $4.0(0.5-33.3)$ & $0.9(0.9-1.0)$ \\
\hline \multicolumn{7}{|c|}{ Hemodynamic SOFA } \\
\hline$\geq 1$ & $64.9(51.7-78.2)$ & $56.5(4||-7 \mid .9)$. & $64.9(51.7-78.2)$ & $56.5(41.1-72.0)$ & $1.5(1.0-2.2)$ & $0.6(0.4-1.0)$ \\
\hline$\geq 2$ & $64.9(51.7-78.2)$ & $60.9(45.7-76.1)$ & $67.3(54.0-80.6)$ & $58.3(43.3-73.3)$ & $1.7(1.1-2.5)$ & $0.6(0.4-0.9)$ \\
\hline$\geq 3$ & $63.2(49.8-76.6)$ & $63.0(48.0-78.1)$ & $67.9(54.4-81.4)$ & $58.0(43.3-72.7)$ & $1.7(1.1-2.6)$ & $0.6(0.4-0.9)$ \\
\hline
\end{tabular}

SOFA: Sequential Organ Failure Assessment; CPK: Creatine phosphokinase; Cl: Confidential interval

extent of muscle damage was represented using various CPK cutoff points to identify at-risk populations. ${ }^{[20]}$ Identifying at-risk patients would allow early treatment strategies to be initiated in patients as appropriate.

In our study, acute kidney injury at the time of the diagnosis of rhabdomyolysis, as measured by the SOFA score, occurred in $37.8 \%$ of patients, with $55.3 \%$ of patients having creatinine values $\geq 1.2 \mathrm{mg} / \mathrm{dL}$ during the rhabdomyolysis episode. The incidence of kidney injury reported in the literature ranges from $4.7 \%$ to $94 \%,[7,9,10,21]$ a variation that probably stems from the different patient populations evaluated and from differences in how rhabdomyolysis and acute renal dysfunction are defined. Whether these percentages reflect the natural progression of the rhabdomyolysis or the effects of treatments or concomitant conditions is unknown.

We evaluated the univariate relationship between kidney injury and demographic, injury, and organ dysfunction variables. We did not find significant differences $(P=0.06)$ in age distribution and the development of this complication, indicating that no age is immune to the risk of kidney injury. We also found no relationship with the Charlson index or with previous hypertension probably because of the population's low comorbidity. As in other research, ${ }^{[18,22]}$ the uric acid levels were more elevated in patients with renal dysfunction.

There is no consensus in the literature as to what marker best identifies rhabdomyolysis and which one can be used to monitor these patients. We used CPK due to the ease of the associated laboratory test. Patients with moderately high CPK levels during the rhabdomyolysis had a lower incidence of kidney injury compared to patients with higher levels of CPK. This is consistent with findings in other studies. ${ }^{[18]}$ The figure for peak CPK, however, did not turn out to be a good predictor of kidney injury in the multivariate analysis, which had a low discriminatory capacity as evidenced by an AUC-ROC of 0.63 [Figure 1]. There are differences in the literature regarding the usefulness of this variable as a predictor of complications. Beetham ${ }^{[20]}$ found that CPK levels $\geq 5000 \mathrm{IU} / \mathrm{L}$ could mark the cutoff point for the development of kidney injury. In the work by Sharp et al. ${ }^{[19]} \mathrm{CPK}$ values $\geq 5000 \mathrm{IU} / \mathrm{L}$ measured at admission were not predictors of renal dysfunction in critical surgical patients.

The multivariate analysis in our study shows that serum creatinine values at admission and the presence of hypotension on the $1^{\text {st }}$ day in the ICU are related to the presence of renal dysfunction during the rhabdomyolysis episode. This is in keeping with the findings reported in other patient populations. ${ }^{[9,18,19,23]}$

The serum creatinine value measured on admission to the hospital is probably related to preexisting kidney injury and to the preadmission treatment though we did not find differences in the initial rehydration regimens in the two groups. In the multivariate analysis, its effect was statistically significant $(P=0.006)$, with a good discriminative capacity to predict kidney injury and an AUC-ROC of 0.91. Initial creatinine values $\geq 1.1$ show good sensitivity (77.2\%; 95\% CI: 65.4-89.0), specificity (89.1\%; 95\% CI: 79.1-99.2), and adequate positive $(89.8 \%$; $95 \%$ CI: $80.3-99.3)$ and negative $(75.9 \%$, 95\% CI: 63.6-88.3) predictive values. 


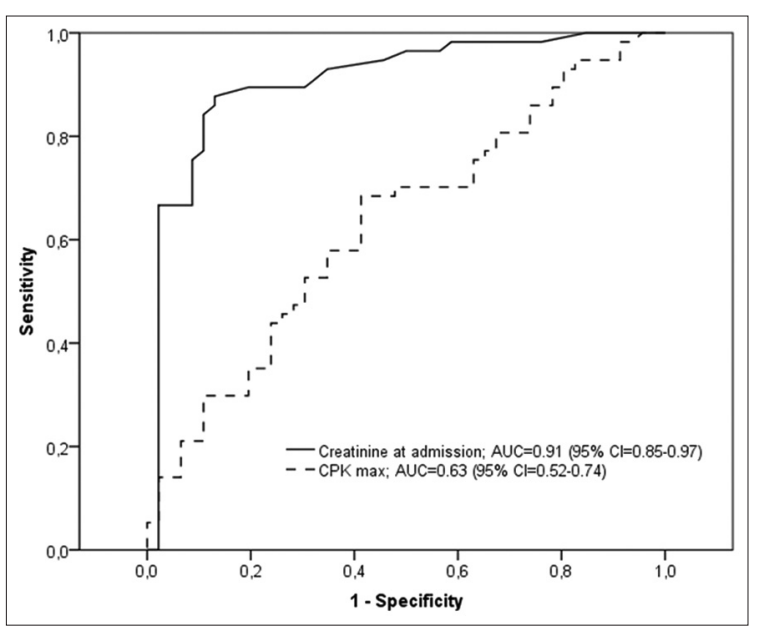

Figure I: Receiver operating characteristics curve for predicting renal dysfunction based on values of creatinine at admission and maximum creatine phosphokinase during stay

Previous studies in diverse patient populations ${ }^{[18,24,25]}$ have pointed to dehydration and systemic hypotension as important factors. Morris et al. ${ }^{[26]}$ found that inadequate resuscitation contributed to kidney injury requiring hemodialysis. In our series, cardiovascular deterioration in the days immediately following the trauma in patients with acute SCIs and rhabdomyolysis were linked independently to kidney injury after adjusting for conventional variables. The hypotension immediately following the trauma probably involves a series of genetic and immune biological phenomena, cardiovascular ability to respond to the trauma, neurogenic damage after the SCI, presence of comorbidities, and initial treatment. Our results, however, show that the posttraumatic hemodynamic dysfunction does not invariably progress to renal dysfunction, with a sensitivity and specificity of around $60 \%$ for a hemodynamic SOFA $\geq 1$.

Of the 57 patients $(55.3 \%$ of the patients with rhabdomyolysis) who developed kidney injury in our series, none required hemodialysis and all regained kidney function with conservative treatment. This is probably related to the population type (young and with a low comorbidity index), range of CPK values, and absence of nephrotoxic cofactors that are present in other types of rhabdomyolysis.

The mortality of patients with rhabdomyolysis was almost $3 \%$, and the death rate had no direct relationship to the rhabdomyolysis or acute kidney injury. Kidney injury by itself was not a predictor of mortality in this series, probably due to the low impact on renal function.

To the best of our knowledge, this is the first series that studies the prevalence and prognosis of rhabdomyolysis in patients with acute traumatic SCI requiring admission to an ICU. Our study was somewhat limited by its reliance on data from a single hospital and by its retrospective nature. We studied a small number of patients, but we included all those with SCIs and rhabdomyolysis over a given period. These patients were all subjected to the same diagnostic criteria and received similar treatments, which increase the internal validity of the study. While the retrospective nature of the study makes it vulnerable to information bias from inaccurate clinical records and missing data, the fact that the patients were in critical condition from the time of admission resulted in exhaustive clinical and laboratory analysis information. Finally, although residual confounding might be present, information regarding different sociodemographic and clinical variables was recorded and adjusted for in a multivariate regression analysis.

\section{Conclusion}

Rhabdomyolysis is a frequent $(51.5 \%)$ and early condition in patients with acute traumatic SCI who were admitted to ICU and renal dysfunction occurred in over half of the cases $(55.34 \%)$ though the prognosis is good. These data suggest that diagnostic markers should be requested starting at the admission. Initial creatinine values $\geq 1.1 \mathrm{mg} / \mathrm{dL}$ yielded a sensitivity of $77.2 \%$ and a specificity of $89.1 \%$ for the appearance of renal dysfunction. In contrast, neither the peak CPK values nor the hemodynamic SOFA score in the first $24 \mathrm{~h}$ exhibited a cutoff point that could be used to properly discriminate between patients with and without renal dysfunction.

\section{Financial support and sponsorship Nil.}

\section{Conflicts of interest}

There are no conflicts of interest.

\section{References}

1. Penn AS, Rowland LP, Fraser DW. Drugs, coma, and myoglobinuria. Arch Neurol 1972;26:336-43.

2. Giannoglou GD, Chatzizisis YS, Misirli G. The syndrome of rhabdomyolysis: Pathophysiology and diagnosis. Eur J Intern Med 2007;18:90-100.

3. Huerta-Alardín AL, Varon J, Marik PE. Bench-to-bedside review: Rhabdomyolysis - An overview for clinicians. Crit Care 2005;9:158-69.

4. Sauret JM, Marinides G, Wang GK. Rhabdomyolysis. Am Fam Physician 2002;65:907-12.

5. Hamel Y, Mamoune A, Mauvais FX, Habarou F, Lallement L, Romero NB, et al. Acute rhabdomyolysis and inflammation. J Inherit Metab Dis 2015;38:621-8.

6. Shapiro ML, Baldea A, Luchette FA. Rhabdomyolysis in the intensive care unit. J Intensive Care Med 2012;27:335-42.

7. Gabow PA, Kaehny WD, Kelleher SP. The spectrum of rhabdomyolysis. Medicine (Baltimore) 1982;61:141-52. 
8. Melli G, Chaudhry V, Cornblath DR. Rhabdomyolysis: An evaluation of 475 hospitalized patients. Medicine (Baltimore) 2005;84:377-85.

9. Veenstra J, Smit WM, Krediet RT, Arisz L. Relationship between elevated creatine phosphokinase and the elinical spectrum of rhabdomyolysis. Nephrol Dial Transplant 1994;9:637-41.

10. Brown CV, Rhee P, Chan L, Evans K, Demetriades D, Velmahos GC. Preventing renal failure in patients with rhabdomyolysis: Do bicarbonate and mannitol make a difference? J Trauma 2004;56:1191-6.

11. Zimmerman JL, Shen MC. Rhabdomyolysis. Chest 2013;144:1058-65.

12. Homsi E, Barreiro MF, Orlando JM, Higa EM. Prophylaxis of acute renal failure in patients with rhabdomyolysis. Ren Fail 1997;19:283-8.

13. Feinfeld DA, Cheng JT, Beysolow TD, Briscoe AM. A prospective study of urine and serum myoglobin levels in patients with acute rhabdomyolysis. Clin Nephrol 1992;38:193-5.

14. Kirshblum SC, Biering-Sørensen F, Betz R, Burns S, Donovan W, Graves DE, et al. International standards for neurological classification of spinal cord injury: Cases with classification challenges. Top Spinal Cord Inj Rehabil 2014;20:81-9.

15. Baker SP, O'Neill B, Haddon W Jr., Long WB. The injury severity score: A method for describing patients with multiple injuries and evaluating emergency care. J Trauma 1974;14:187-96.

16. Teasdale G, Maas A, Lecky F, Manley G, Stocchetti N, Murray G. The Glasgow Coma Scale at 40 years: Standing the test of time. Lancet Neurol 2014;13:844-54.

17. Antonelli M, Moreno R, Vincent JL, Sprung CL, Mendoça A,
Passariello M, et al. Application of SOFA score to trauma patients. Sequential Organ Failure Assessment. Intensive Care Med 1999;25:389-94

18. Ward MM. Factors predictive of acute renal failure in rhabdomyolysis. Arch Intern Med 1988;148:1553-7.

19. Sharp LS, Rozycki GS, Feliciano DV. Rhabdomyolysis and secondary renal failure in critically ill surgical patients. Am J Surg 2004;188:801-6.

20. Beetham R. Biochemical investigation of suspected rhabdomyolysis. Ann Clin Biochem 2000;37(Pt 5):581-7.

21. Sulowicz W, Walatek B, Sydor A, Ochmanski W, Milkowski A, Szymczakiewicz-Multanowska A, et al. Acute renal failure in patients with rhabdomyolysis. Med Sci Monit 2002;8:CR24-7.

22. Fernández-Fúnez A. Acute renal failure in rhabdomyolysis. Rev Clin Esp 1998;198:758-64.

23. Fernandez WG, Hung O, Bruno GR, Galea S, Chiang WK. Factors predictive of acute renal failure and need for hemodialysis among ED patients with rhabdomyolysis. Am J Emerg Med 2005;23:1-7.

24. Grossman RA, Hamilton RW, Morse BM, Penn AS, Goldberg M. Nontraumatic rhabdomyolysis and acute renal failure. N Engl J Med 1974;291:807-11.

25. Chugh KS, Singhal PC, Nath IV, Pareek SK, Ubroi HS, Sarkar AK. Acute renal failure due to non-traumatic rhabdomyolysis. Postgrad Med J 1979;55:386-92.

26. Morris JA Jr., Mucha P Jr., Ross SE, Moore BF, Hoyt DB, Gentilello L, et al. Acute posttraumatic renal failure: A multicenter perspective. J Trauma 1991;31:1584-90. 